documentation research and indicated how poorly this field was supported in Britain. Dr. R. M. Lodge, research manager of British Nylon Spinners, Ltd., spoke on the communication network in an industrial organization and indicated the difficulties of presenting technical information at many different levels within the firm.

The mass media of communication-press, radio, television, films, exhibitions and conferences-were each dealt with in turn by acknowledged experts. It was generally accepted that the primary value of radio, television and films was in creating a healthy climate of opinion to encourage scientific and technical development. Dr. T. Margerison, science editor of the Sunday Times, felt that more use could be made of television by the inclusion of news reports of scientific and industrial developments in magazinetype programmes, and the possibility of implanting the germ of an idea in this way should not be overlooked. Mr. P. Cudlipp, editor of the New Scientist, reviewing the function of the general science journal, stressed the value of scientists and technologists keeping themselves broadly informed on a wide range of scientific disciplines. He referred also to the need for scientists themselves to take $\mathrm{a}$ hand in the preparation of material that the layman could understand, and noted the growing number of science correspondents in the popular press-which was a recognition of the public interest in science. A better balance and more careful reporting of science news had been achieved, but there was still room for improvement. Exhibitions and conferences were dealt with by Mr. E. H. Underwood, the director of public relations for the U.K. Atomic Energy Authority, who stressed the importance of defining objectives and the audience aimed at, but once again, however, personal contact was cited as being very often the most valuable result of attending such functions. Mr. E. Anstey, of the British Transport Commission, and president of the Scientific Film Association, spoke on "Films to Illuminate and Persuade", directing attention to the use of film as a tool not only for spreading scientific knowledge but also for the popular understanding of science.

In a paper by Mr. L. W. Stevens-Wilson, head of the Steel Users Section, British Iron and Steel Research Association, attention was directed to the need for closer collaboration between specialist or vertically oriented technical information services and horizontal or regionally based services. The Department of Scientific and Industrial Research was strongly recommended to set up more branch offices, similar to those existing in Cardiff and Edinburgh.

The widely differing views of delegates and the relative value of the different methods of communicating information made it clear that there is no one ideal solution to the problem. It would appear that there is still need to strengthen all existing techniques. There was general agreement that in many sectors of industry the prevailing level of interest in research and development was not very high, and that the outstanding difficulty was not simply to improve the means of transmitting scientific and technical information but to stimulate interest at the receiving end in industry. How this was to be achieved remained largely an open question, but it must involve a strong element of personal contact to make an effective change in the habits of thought and climate of opinion in both industry and science.

E. E. Williams

\title{
AN INTERNATIONAL ANDEAN YEAR
}

$\mathrm{O}^{\mathrm{s}}$ $\mathrm{N}$ the initiative of Unesco and by invitation of Dr. Angel Establier, head of the Scientific Office in Montevideo of that Organization in Latin America, who has been interested in such a project from its beginning, a meeting was held in Buenos Aires, during April 3-4, to discuss the planning of an International Andean Year. During such a programme, an intensive study would be carried out on the range of mountains known as the Cordillera de los Andes, from Panama to the southern part of the continent. A small number of scientists from different countries interested were present: Dr. H. O'Reilly Sternberg (Brazil); Dr. Guillermo Mann (Chile); Dr. Tobfas Lasser (Venezuela); Dr. Ovidio Suarez (Bolivia); Eng. Eduardo Baglietto, General M. Olascoaga and Drs. F. Bonorino Udaondo, J. Roederer, Angel Cabrera, M. Sadosky, B. A. Houssay and V. Deulofeu, all from Argentina. Dr. A. Hurtado, from Peru, unfortunately could not attend. Dr. A. Establier represented Unesco and his office will be the centre for the various groups in preparing the project.

After an introductory welcome by the vice-dean of the Faculty of Exact and Natural Sciences at Buenos Aires, Dr. M. Sadosky, Dr. Venancio Deulofeu was elected chairman and Dr. Establier acted as advisory secretary. Four sessions were held.

All present agreed in considering that the project to institute an International Andean Year will be of great importance not only because of its width of interest and of the scientific results which are likely to accrue, but also because of the number of scientists involved and the expected international participa. tion from countries outside South America. It was also considered that a project of this magnitude will have a favourable impact on the progress of science and the future scientific development of most of the South American countries.

Discussions dealt with the fields which it would be desirable to cover during the International Andean Year. As a preliminary list it was considered possible and convenient to work on the following subjects: 1, geology ; 2, botany; 3, geophysics ; 4, human biology ; 5, zoology; 6, human ecology; 7, geomorphology including glaciology; 8, physies of high altitudes; 9 , soil sciences; 10, geography; 11, agronomic sciences (in collaboration with the Food and Agriculture Organization); 12, sociology; 13, ethnography (both 12 and 13 in collaboration with institutes of social sciences); 14, archæology; 15, anthropology; 16, economics (in collaboration with the Comision Económica para América Latina).

In each of these fields some subdivisions have already been made and, as an example of the type of work which would be involved, some specific projects were mentioned. For example, it was suggested that in studying the geology of the Andes, it would be desirable to concentrate the efforts in examining the evolution of the Andean range, especially the tectonic 
and magmatic cycles of the Andean syncline, tertiary and quaternary vulcanism and the magmatic provinces in the Andes.

A further meeting is being planned for December 1961, and will be held in Santiago de Chile, to consider reports to be presented by the scientists participating in the meeting in Buenos Aires and to elaborate further and develop the specific projects in each scientific field.

In the meantime, the Unesco Scientific Office in Montevideo will start compiling a bibliography of research done on the Andes, and collecting the names of acientists who have been active in that field, or who, by their training, are likely to be interested in participating in any of the activities planned for the International Andean Year.

Further information on this project can be obtained from Dr. A. Establier, Centro de Cooperaciôn Científica de la Unesco para América Latina, Boulevard Artigas 1320, Montevideo, Uruguay.

V. Deulofeu

\section{SOLAR VARIATIONS, CLIMATIC CHANGE AND RELATED GEOPHYSICAL PROBLEMS}

Un NDER the above title, a symposium was arranged by the New York Academy of Sciences, through the Academy's Section of Geological Sciences and its Division of Oceanography and Meteorology, in cooperation with the American Meteorological Society. The meetings were held in New York during January 24-28. The papers given at the symposium are to be published by the Academy in a fortheoming volume of its Annals.

Understandably, the United States provided about four-fifths of the sixty or so participants who offered papers or contributed to the discussions, but a number of workers active in the fields covered by the symposium were present from Canada, the United Kingdom, Holland, Germany and Hungary. Swedish, Russian and Australian contributions had been invited, but their authors were unable to be present. Abstracts of the papers were provided and the meeting as a whole was admirably organized. The generous hospitality of the New York Academy of Sciences was indeed a feature.

The organization of the conference and the arrangements for overseas visitors were largely in the hands of Dr. Rhodes W. Fairbridge, professor of geology at Columbia University, to whom indeed a great part of the success of the meeting was due. Dr. Fairbridge's arguments for the relationship of changes of sea-level, great and small, to the fluctuations of climate which have affected and continue to affect the volume of the Earth's ice-sheets and glaciers, have become widely known (cf. his recent article in Scientific American, 202, No. 5, 70; 1960). A fuller statement has now been published in Physics and Chemistry of the Earth, 4 (Pergamon Press, 1961). Developing as they do from his earlier work on the eustatic changes shown on the cosst of West Australia, they integrate a vast amount of carefully assembled field evidence on a world-wide scale and, cautiously yet persuasively presented, they will be found acceptable by many workers. Nevertheless, it can be agreed that we do not yet know enough about the other agencies that may have affected the volume of the hollows in which the oceans lie.

Climatic change is demonstrably a subject with exceptional ramifications, and the contributions of a great many scientists from differing disciplines are repeatedly called for. Accordingly, the scope of the symposium was enormously wide, beginning with six papers on solar physics under the chairmanship of Dr. Donald H. Menzel (Harvard University). Climatic effects potentially attributable to solar variation were discussed under the chairmanship of Dr. Sigmund Fritz, replacing Dr. H. Wexler, who could not be present. It is evident that the only effects of solar variation that are so far generally accepted are those observable in the extreme ultra-violet end of the solar spectrum, affecting the high atmosphere and the Earth's magnetic field, although some of the apparent relationships with atmospheric circulation patterns are sufficiently suggestive to justify further attention. Among a variety of papers on various aspects of the radiation balance and the general circulation, $H . H$. Lamb (Meteorological Office, Harrow) presented some of his recent work on displacements of the circulation pattern (cf. Geografiska Annaler, 1960). A further session was devoted to meteorological satellites. Dr. Helmut E. Landsberg (United States Weather Bureau) took the chair at a session entitled "Glaciology, Oceanography and Climatology"; here Dr. William L. Donn presented a summary of the EwingDonn theory of the ocean control of Quaternary climate (Science, 1958), unfortunately with insufficient time for discussion of a controversial topic in which many would gladly have joined. A preceding paper by Dr. T. N. V. Karlstrom (Coast and Geodetic Survey, Washington) on the glacial history of Alaska provided evidence manifestly difficult to reconcile.

With Dr. R. F. Flint (Yale University) in the chair, followed by Dr. E. S. Deevey (Yale University), palæoclimatology came under review, including several papers around the theme of palynology. Dr. E. H. Willis (University of Cambridge) commented on some of the Fenland evidence. Among the most interesting contributions was that of Dr. Calvin Heusser (Amerioan Geographical Society), who gave evidence for the approximate contemporaneity of Late- and Post-Glacial events in the Rockies and the Southern Andes. With Prof. F. E. Zeuner (University of London) in the chair, a final session was devoted to papers around the theme of "Climatic Change and Man". Archrological studies in the United States and in the Near East were noteworthy; Dr. Ralph Solecki's discussion of some of the preliminary findings at the Shanidar cave in Northern Iraq was of great interest, and attracted attention.

It will be evident from this brief summary that a remarkable diversity of papers came up for discussion. Throughout the symposium the impression prevailed that there are many who are still hopeful that some kind of periodicity will appear, based on such solar manifestations as we can observe. From others, dispiriting criticisms equally abound. Dr. Reid Bryson (University of Wisconsin), for example, has applied modern statistical methods to the analysis of tree-ring spectra and found that the usual sunspot cycles fail to appear. On the other hand, several 